\title{
Computed tomography-guided patent blue vital dye localization of pulmonary nodules in uniportal thoracoscopy
}

\author{
Mong-Wei Lin, MD, PhD, ${ }^{\mathrm{a}}$ Yao-Hui Tseng, MD, ${ }^{\mathrm{b}}$ Yee-Fan Lee, MD, ${ }^{\mathrm{b}}$ Min-Shu Hsieh, MD, \\ Wei-Chun Ko, MD, ${ }^{b}$ Jo-Yu Chen, MD, ${ }^{b}$ Hsao-Hsun Hsu, MD, PhD, ${ }^{a}$ Yeun-Chung Chang, MD, PhD, ${ }^{b}$ and \\ Jin-Shing Chen, MD, $\mathrm{PhD}^{\mathrm{a}}$
}

\begin{abstract}
Objective: Due to the limitations of the small single incision, an ideal preoperative localization technique is essential for surgical resection of small pulmonary nodules by uniportal video-assisted thoracoscopic surgery (VATS). The aim of this study is to evaluate the usefulness and safety of preoperative computed tomography (CT)-guided patent blue vital (PBV) dye localization in patients with small indeterminate pulmonary nodules who have undergone uniportal VATS for lung resection.
\end{abstract}

Methods: In this retrospective study, 177 consecutive patients (196 pulmonary nodules) who underwent preoperative CT-guided PBV dye localization and uniportal VATS from January 2013 to September 2015 were enrolled.

Results: The CT-dye localization procedure was performed successfully and correctly for $99.5 \%(195 / 196)$ of the nodules within a mean procedure time of 30 minutes. The mean size of the nodules was $7.8 \mathrm{~mm}$, and their mean depth from the pleural surface was $18.3 \mathrm{~mm}$. Most of the nodules $(78.6 \%, 154 / 196)$ were pure ground-glass nodules (GGNs) and part-solid GGN with ground-glass opacity (GGO) of $50 \%$ or more. Asymptomatic pneumothorax occurred in $29.4 \%(52 / 177)$ of patients after the localization procedure, but none required invasive treatment. All nodules were successfully resected using uniportal VATS without any conversion to thoracotomy. The postoperative course was smooth, with a short mean hospital stay ( $3.3 \pm 1.2$ days) and a low morbidity rate $(0.6 \%, 1 / 177)$.

Conclusions: Preoperative CT-guided PBV dye localization is a feasible, safe, and accurate procedure. It makes uniportal VATS easy for small, poorly located pulmonary nodules with GGO predominance and synchronous multiple nodules. (J Thorac Cardiovasc Surg 2016;152:535-44)

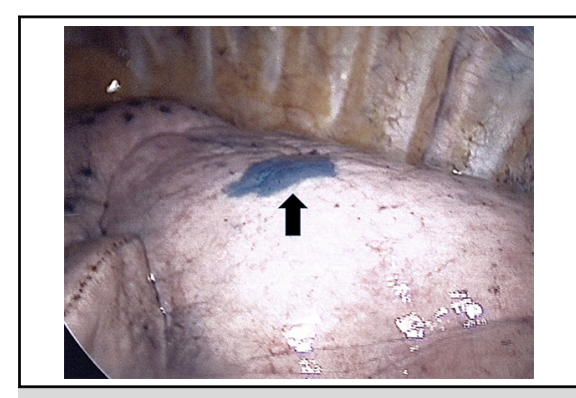

Thoracoscopic view of the indeterminate lung nodule localized by CT-guided PBV dye.

\section{Central Message}

CT-guided PBV dye localization for uniportal VATS is safe and feasible, and results in a short hospital stay and low morbidity rate.

\section{Perspective}

Preoperative CT-guided patent blue vital dye localization is a feasible, safe, and accurate procedure. It makes uniportal video-assisted thoracoscopic surgery easy for small, poorly located nodules, those with ground-glass opacity, and synchronous multiple nodules, and results in a smooth postoperative course with a short hospital stay $(3.3 \pm 1.2$ days) and low morbidity rate $(0.6 \%, 1 / 177)$.

See Editorial Commentary page 545.

\footnotetext{
From the Departments of ${ }^{\text {a }}$ Surgery, ${ }^{b}$ Medical Imaging, and ${ }^{c}$ Pathology, National Taiwan University Hospital and National Taiwan University College of Medicine, Taipei, Taiwan.

Y.-C. Chang and H.-H. Hsu contributed equally to this work.

The study was supported by research grants from the Ministry of Science and Technology, Taiwan (NSC103-2325-B-002-014) and National Taiwan University Hospital, Taipei, Taiwan (NTUH105-003233, HCH 103-024).

Received for publication Feb 1, 2016; revisions received March 26, 2016; accepted for publication April 16, 2016; available ahead of print May 14, 2016.

Address for reprints: Yeun-Chung Chang, MD, PhD, Department of Medical Imaging, National Taiwan University Hospital and National Taiwan University College of Medicine, No. 7, Chung-Shan South Rd, Taipei 10002, Taiwan (E-mail: ycc5566@ntu.edu.tw). Or: Hsao-Hsun Hsu, MD, PhD, Department of Surgery, National Taiwan University Hospital and National Taiwan University College of Medicine, No. 7, Chung-Shan South Rd, Taipei 10002, Taiwan (E-mail: ntuhsu@gmail.com).

$0022-5223 / \$ 36.00$

Copyright (c) 2016 by The American Association for Thoracic Surgery

http://dx.doi.org/10.1016/j.jtcvs.2016.04.052
}

Advances in high-resolution computed tomography (CT) imaging and the availability of low-dose CT screening for lung cancer detection in asymptomatic patients are increasing the detection rate for small pulmonary nodules in the peripheral lung parenchyma. ${ }^{1,2}$ Most of these CTdetected pulmonary nodules are indeterminate, including lesions characteristic of pure ground-glass nodules

Scanning this QR code will take you to supplemental figures and video for this article. 


\section{Abbreviations and Acronyms}

$\begin{array}{ll}\text { CT } & =\text { computed tomography } \\ \text { GGN } & =\text { ground-glass nodule } \\ \text { GGO } & =\text { ground-glass opacity } \\ \text { ICU } & =\text { intensive care unit } \\ \text { PBV dye } & =\text { patent blue vital dye } \\ \text { VATS } & =\text { video-assisted thoracoscopic surgery }\end{array}$

(GGNs), part-solid GGNs, and pure solid nodules. ${ }^{1,2}$ A histopathologic diagnosis is required, especially when the nodule persists and has a solid component $\geq 5 \mathrm{~mm}$, or the nodule has enlarged on follow-up CT scans. ${ }^{3}$

The accurate early diagnosis of these nodules is challenging. Performing CT-guided percutaneous biopsy of these indeterminate nodules is often difficult when the nodule size is $2 \mathrm{~cm}$ or less, has predominantly groundglass opacity (GGO), or is located in a site that is difficult to reach. ${ }^{4,5}$ Surgical open-lung biopsy used to be the goldstandard diagnostic modality, both for curative resection and diagnostic procedures. However, with the advances in video-assisted thoracoscopic surgery (VATS) in the 1990s, lung biopsies are increasingly done by VATS because of shorter hospital stays, less tissue injury, and better cosmetic results. ${ }^{6,7}$

Recently, uniportal VATS for major lung resections has been used in the treatment of lung tumors. ${ }^{8,9}$ GonzalezRivas and colleagues ${ }^{8}$ reported the first uniportal VATS lobectomy in 2011. Since then, more complicated procedures including segmentectomy, pneumonectomy, and sleeve resection have been reported. ${ }^{9}$ The procedure is done through only one 3- to 4-cm incision. ${ }^{9}$ In cases of complicated anatomic lung resection, it may be more difficult to resect a small or deeply located pulmonary nodule with a predominantly GGO component by uniportal VATS. This is because the nodule may be thoracoscopically invisible and impalpable with uniportal VATS. Therefore, preoperative localization of these nodules is mandatory for successful uniportal VATS lung resection.

Various localization techniques for traditional 3-port VATS for pulmonary nodule resections have been reported. These techniques include intraoperative digital palpation of nodules elevated by thoracoscopic instruments, intraoperative ultrasonographic localization, and preoperative localization with CT-guided methods. ${ }^{10-27}$ With uniportal VATS, intraoperative digital palpation and intraoperative ultrasonography are difficult to perform via a small 3- to 4-cm incision. Thus, preoperative localization is essential. There are several preoperative CTguided methods for localization using various materials. $^{10-27}$ Each method has its advantages and disadvantages. CT-guided hookwire localization has been widely used because of its safety and efficacy. ${ }^{15-18}$
However, the major drawback is frequent dislodgment of the hookwire from its perinodular location. ${ }^{15-18}$ The hookwire may dislodge when lung atelectasis occurs as part of the biopsy process as well as when 1 lung ventilates during the operation. In the era of uniportal VATS, dislodgement sometimes occurred during lung manipulation because of the limitations of a single incision and simultaneous use of multiple thoracoscopic instruments. Therefore, CT-guided hookwire localization is not ideal for use with uniportal VATS.

In our institute, we routinely used CT-guided hookwire localization for indeterminate small pulmonary nodules before starting uniportal VATS, and then we shifted to CT-guided PBV dye localization when we began to perform uniportal VATS in 2013. The efficacy and safety of CTguided PBV dye localization with uniportal VATS has not been reported previously. Thus, we conducted this retrospective study to evaluate the usefulness and safety of preoperative CT-guided PBV dye localization of 196 small, indeterminate pulmonary nodules in 177 patients who underwent uniportal VATS lung resection.

\section{MATERIALS AND METHODS \\ Patients}

The medical records of 1075 consecutive patients who underwent thoracoscopic surgery for pulmonary resection by a single thoracic surgical team using the same clinical protocols, care patterns, and perioperative orders at National Taiwan University Hospital from January 2013 to September 2015 were reviewed retrospectively. Of these, preoperative CT-guided dye localization for undiagnosed pulmonary nodules was performed in 283 patients and, of them, 177 who underwent uniportal VATS lung resection were enrolled in the study (Figure 1 shows the algorithm for patient selection). The Research Ethics Committee of the National Taiwan University Hospital approved this study (project approval number 201510121RIND).

At our institute, preoperative CT-guided dye localization was potentially indicated for patients with incidentally found, small, undiagnosed pulmonary nodules, including pure GGNs, part-solid GGNs, and solid nodules. The surgical indications for these patients included enlargement of the nodule size on follow-up CT images and persistence of a nodule with a solid component of $5 \mathrm{~mm}$ or more on the follow-up CT images. In patients with stationary nodules with a solid component less than $5 \mathrm{~mm}$, tumor excision was performed at the patient's request due to anxiety but only after 1 year of follow-up. This preoperative localization procedure was performed when both the surgeons and radiologists considered that these nodules were not likely to be visualized intraoperatively during thoracoscopy. All patients stopped taking anticoagulant drugs at least 5 days before surgery, had normal prothrombin and activated partial thromboplastin times, and had platelet counts of more than $80 \times 10^{3} / \mu \mathrm{L}$.

Clinical parameters, including age, gender, smoking status, nodule size, nodule site, nodule numbers, preoperative CT-guided localization-related parameters, surgical procedure (wedge resection, segmentectomy, or lobectomy), anesthetic method (intubated anesthesia or nonintubated anesthesia), operation duration, operative blood loss, lengths of postoperative intensive care unit (ICU) and postoperative hospital stays, postoperative chest tube duration, and in-hospital morbidity and mortality were collected from patients' charts. The histopathology of the resected nodules was classified according to the criteria set by the World Health Organization in 2015. The GGO percentage of a nodule was determined by comparison with a standard picture archive and communication system using a 


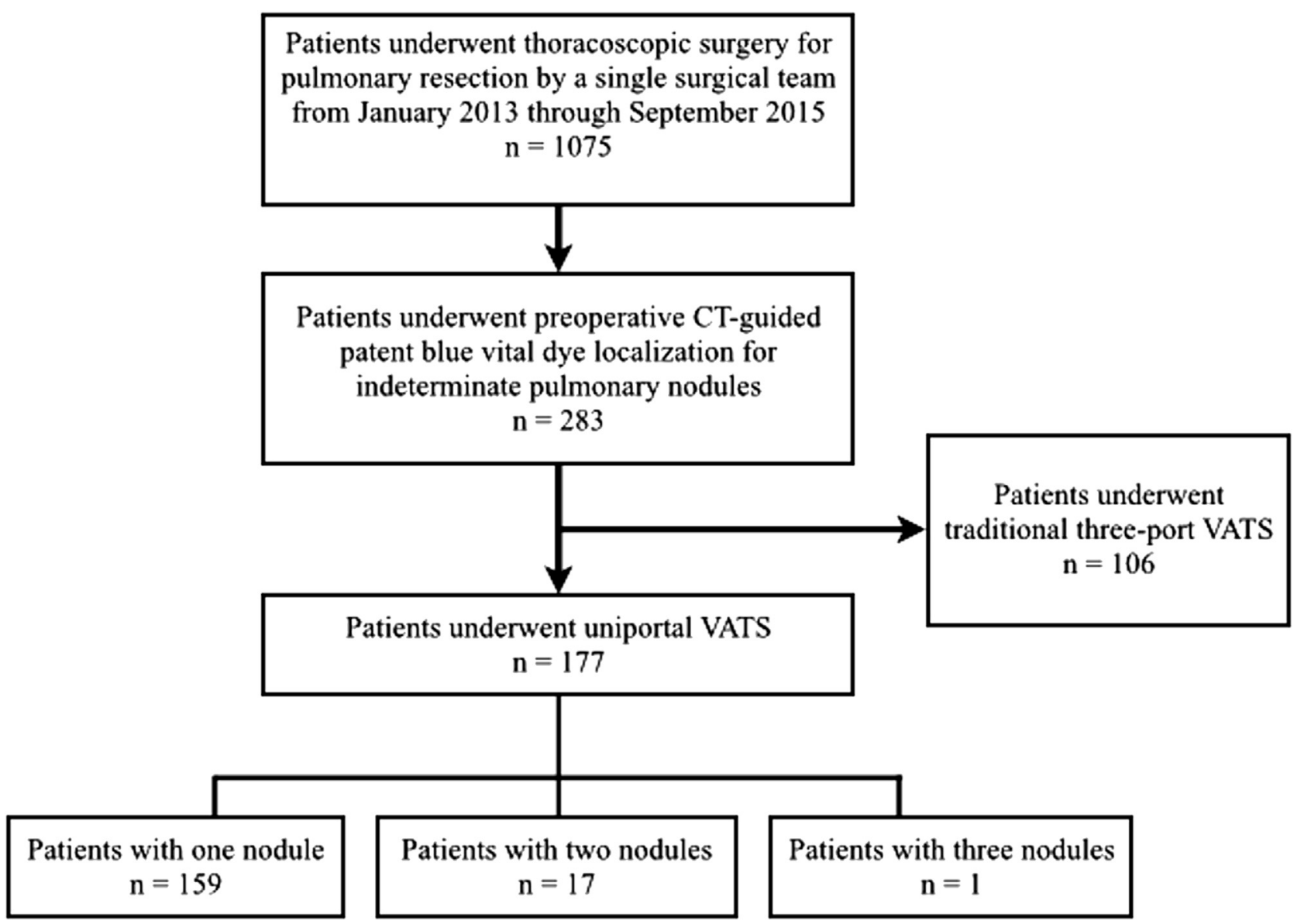

FIGURE 1. Algorithm for patient selection. CT, Computed tomography; VATS, video-assisted thoracoscopic surgery.

commercially available viewer (IMPAX 5.2; Agfa HealthCare, Mortsel, Belgium) by 5 radiologists (Y.-C. Chang, Y.-H. Tseng, Y.-F. Lee, W.-C. Ko, and J.-Y. Chen) and was recorded after they reached a consensus. The GGO percentage was defined as the total volume of the GGO component divided by the total volume of the nodule times 100 . The nodules were further classified into 4 categories according to the results of GGO percentage quantification: pure GGN, part-solid GGN with a GGO percentage of $50 \%$ or more, part-solid GGN with a GGO percentage of less than $50 \%$, and pure solid nodules.

\section{CT-Guided PBV Dye Localization Technique}

Before surgery, CT-guided dye localization with PBV was performed by 1 of 5 board-certified radiologists (Y.-C. Chang, Y.-H. Tseng, Y.-F. Lee, W.C. Ko, and J.-Y. Chen) experienced in CT-guided interventional techniques. All procedures were performed using low-dose settings $(120 \mathrm{kVp}, 50 \mathrm{~mA}$, 1.3 pitch, and 0.7 -second rotation time) without contrast enhancement on a 16-slice instrument (GE LightSpeed; GE Healthcare, Milwaukee, Wis). Images were obtained in $1.25-\mathrm{mm}$ thin sections during the localization procedure.

Patients were placed in a position that allowed the shortest access route for needle insertion. Chest CT was performed first to formulate the plan for the localization procedure. After injecting the local anesthetic (xylocaine $2 \%$; Recipharm Monts, Monts, France) into the thoracic wall, a 22gauge Chiba needle was gradually advanced to the nodule or a nearby location via the shortest access route (Figure 2). Then, approximately $0.2 \mathrm{~mL}$ of PBV dye (patent blue V 2.5\%; Guerbet, Aulnay-sous-Bois, France) contained in a $1-\mathrm{mL}$ syringe was injected into the deepest part of the nodule.
For some patients with a deeply localized nodule, the subpleural lung parenchyma of the localization route was also localized with approximate $0.2 \mathrm{~mL}$ of PBV dye (Figures 3 and 4 ). The procedure was postponed immediately if significant bleeding or a change in vital signs occurred. After removal of the needle, the chest CT images were obtained to assess the dye localization and possible complications, such as pneumothorax,

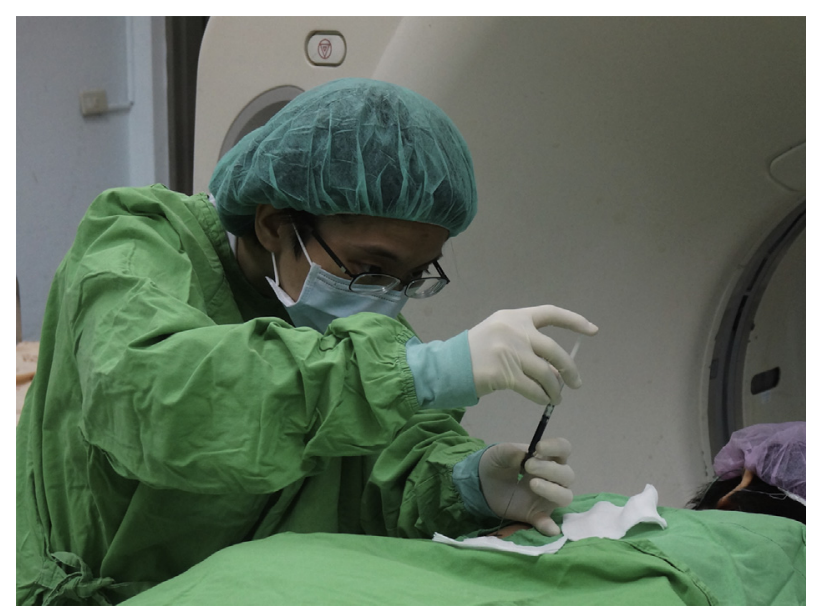

FIGURE 2. The radiologist performing CT-guided PBV dye localization 

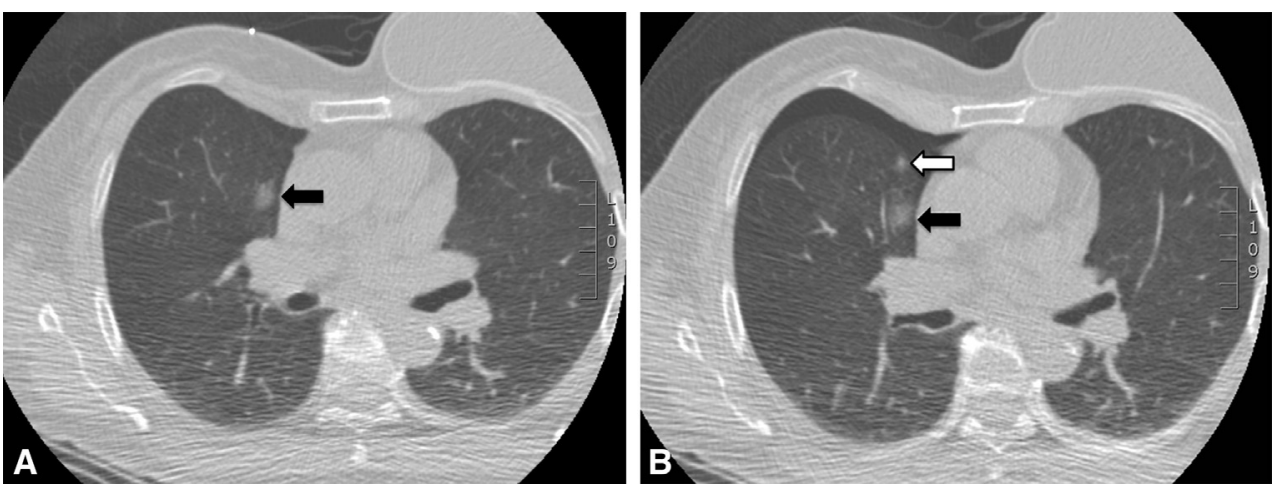

FIGURE 3. A, The arrow indicates a pure ground-glass nodule (GGN) in the right middle lobe. After intraoperative frozen section had confirmed a malignancy, the patient underwent additional uniportal video-assisted thoracoscopic surgery (VATS) lobectomy and systematic lymph node dissection. The final pathology report was invasive adenocarcinoma with a predominant lepidic pattern. B, After localization, the pleural surface of the localization route (hollow arrow) as well as the nodule site (solid arrow) were both marked with patent blue vital (PBV) dye.

intrapulmonary hemorrhage, or hemothorax. The procedure time was defined as the time from initiation of the preprocedural CT scanning to the end of the postprocedural CT scan and was recorded for each patient. Patients were then transported back to the general ward to await surgery.

\section{Uniportal VATS}

The details of the anesthesia protocol for intubated and nonintubated VATS are fully described in previous studies. ${ }^{28-30}$ Briefly, patients underwent nonintubated uniportal VATS using a combination of targetcontrolled sedation, intercostal nerve block, and intrathoracic vagal block. $^{28-30}$ The patient was positioned in the lateral decubitus position after anesthesia. A single 3- to 4-cm skin incision was made in the 5th intercostal space along the anterior axillary line, and a wound protector (Alexis wound protector/retractor; Applied Medical Technology, Brecksville, Ohio) was applied at the incision site. Rib spreading and retractor use were avoided in all patients. A 5-mm, 30-degree video telescope (Karl Stroz, Tuttlingen, Germany) was inserted to explore the pleural cavity. After confirmation of the PBV dye-marked lesion site (Figure 5), wedge resection with an adequate resection margin, if possible, was performed using an endoscopic stapling device. Intraoperative pathologic frozen-section analysis was routinely performed for all patients. Additional anatomic pulmonary resection, including segmentectomy and lobectomy, was performed immediately if a nodule was confirmed to be malignant with a resection margin of less than $20 \mathrm{~mm}$. All the primary lung cancer patients also underwent systematic lymph node dissection using a harmonic scalpel (Ethicon Endo-Surgery, Cincinnati, Ohio) and endoscopic hook electrocautery. After the surgery, the lungs were checked for air leaks by inflation. An intercostal nerve blockade was then established using direct thoracoscopic vision by injection of 1 to $2 \mathrm{~mL}$ of bupivacaine (bupivacaine $0.5 \%$; Recipharm Monts, Monts, France) under the parietal pleura, $2 \mathrm{~cm}$ lateral to the sympathetic chain, from the 3rd to the 8th intercostal spaces using a 25 -gauge, top-winged infusion needle. A 24 - or 28 -French chest tube was placed through the original incision. The operative procedure is demonstrated in Video 1.

\section{Skills for Uniportal VATS Wedge Resection}

It is a challenge for the surgeons to determine how to lay down their staple lines to obtain adequate margins for these deep nonpalpable lesions. Some skills for uniportal VATS wedge resection may be helpful.

We routinely use two 2-0 silk retraction sutures for elevating the nodule sites (Figure E1 and Video 1) under the uniportal VATS. Using a long needle to penetrate the chest wall for anchoring, the silks can be pulled extracorporeally in the direction we decide. The lung parenchyma can be elevated in the best direction to obtain an adequate margin. This method can also avoid the use of the long conventional instruments for lung parenchyma grasping when applying endostaplers.

For those lesions that were deep below the visceral pleural surface, it was not easy to apply the endostaplers directly. In this situation, initially we used electrocautery at one side of the nodule for the separation of lung parenchyma (Figure E1). The initial location for lung parenchyma separation can be identified by PBV dye localization at the subpleural lung parenchyma. Once we approached the nodule site, we could see the

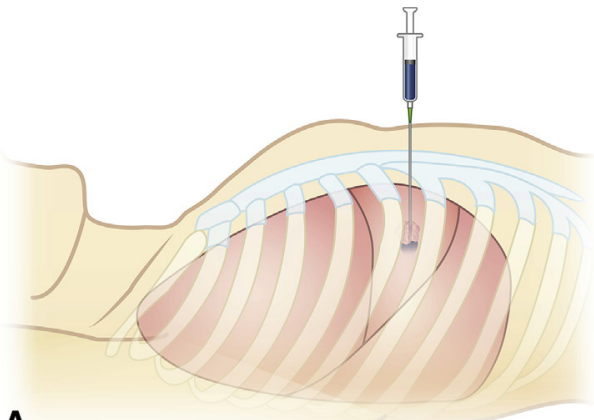

A

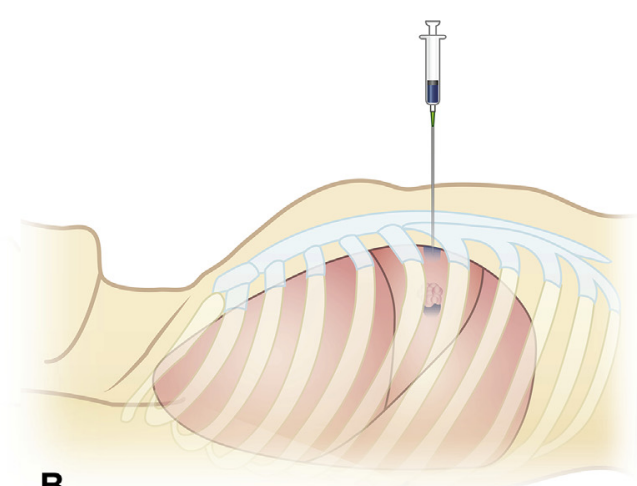

B

FIGURE 4. A, Illustration of the localization procedure in patients with deep nodules. The nodule site or nearby location was first localized by PBV dye injection. The deep margin of the nodule is clearly visible during the operation. B, The subpleural lung parenchyma was subsequently localized by PBV dye injection. 

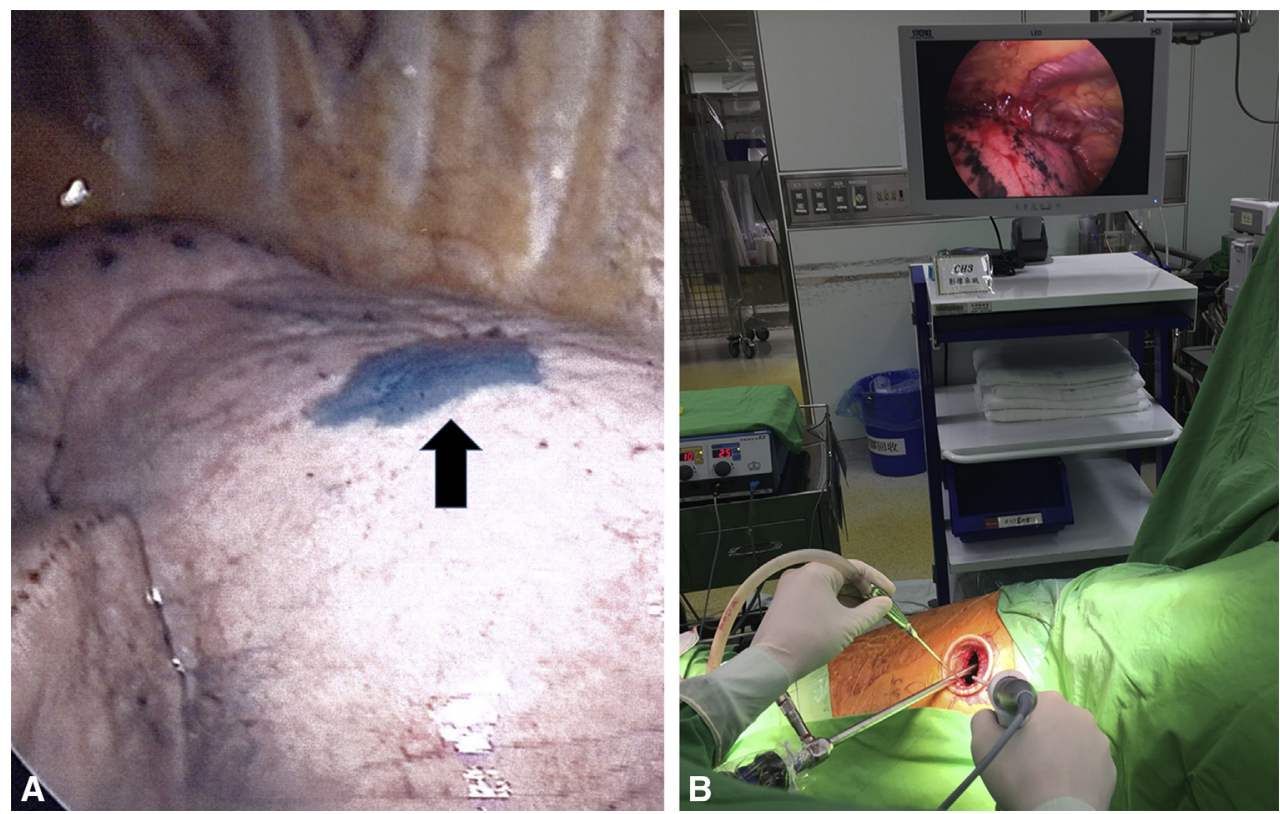

FIGURE 5. A, Thoracoscopic view of the localized lung nodule site (arrow). The margin of the localized site is clear and is clearly visible intraoperatively even 245 minutes after the localization procedure in this case. B, Operative settings for uniportal VATS in our institute. One 3-to 4-cm incision was made in the anterior axillary line in the 5th intercostal space.

blue PBV dye near the deep nodule site. After separating the lung parenchyma at one side of the nodule, we had enough space to apply the endostaplers.

\section{RESULTS}

\section{Characteristics of Patients and Pulmonary Nodules}

Table 1 shows the characteristics of the patients and nodules. The study included 177 patients with 196 pulmonary nodules. Of the 177 patients studied, 44 were male and 133 were female. The mean age of the patients was 56.8 years (range, 24-83 years). Most of the patients were

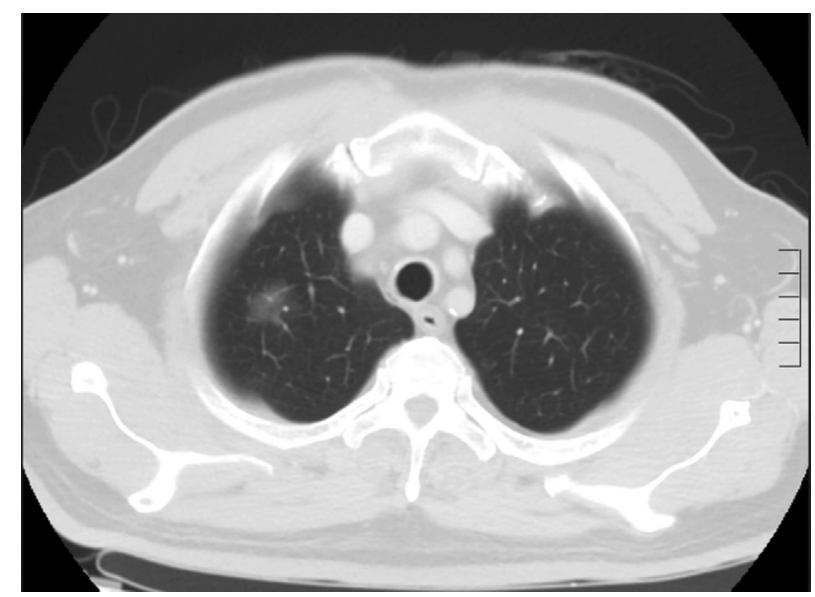

VIDEO 1. The procedure for CT-guided PBV dye localization and uniportal VATS wedge resection. Video available at http://www.jtcvsonline.org/ article/S0022-5223(16)30254-9/addons. nonsmokers $(93.8 \% ; 166 / 177)$, and most of the patients who were smokers were male $(90.9 \% ; 10 / 11)$. Most of the patients $(159 ; 89.8 \%)$ had a single pulmonary nodule. According to the pathology reports, the average size of the nodules was $7.8 \pm 3.4 \mathrm{~mm}$ (range, $2-22 \mathrm{~mm}$ ). Of the 177 patients, $115(58.7 \%)$ and $19(9.7 \%)$ had pure GGNs and pure solid nodules on chest CT, respectively. The remaining patients had part-solid GGNs with GGO of 50\% or more $(19.9 \% ; 39 / 196)$ or part-solid GGNs with GGO less than $50 \%(11.7 \%$; 23/196).

The PBV dye localization did not affect the pathologic diagnosis under hematoxylin and eosin stain or other immunohistochemical stains. Figure E2 shows that the frozen section and the permanent section of the pulmonary nodules was clear for pathologic diagnosis after PBV dye localization. The final surgical pathology of the pulmonary nodules revealed malignant and premalignant disease in $90.9 \%$ $(178 / 196)$ of the nodules and benign disease in only $9.2 \%$ (18/196).

\section{Computed Tomography-Guided Dye Localization}

CT-guided dye localization was performed 197 times for the 196 pulmonary nodules in 177 patients. One patient with 2 pulmonary nodules underwent only 1 localization because of the close distance of the 2 nodules, while 2 patients with 1 pulmonary nodule each underwent 2 localizations. The nodules were located at a mean distance of $18.3 \mathrm{~mm}$ (range, $1-60 \mathrm{~mm}$ ) from the pleural surface to the superficial depth viewed on the $\mathrm{CT}$ image. The CT-guided localization procedure required 30.0 minutes (range, 6-60 minutes) to 
TABLE 1. Characteristics of patients and nodules

\begin{tabular}{|c|c|}
\hline & $\begin{array}{c}\mathrm{N}(\%) \text { or } \\
\text { mean } \pm \text { SD (range) }\end{array}$ \\
\hline Total patient numbers & 177 \\
\hline Total nodule numbers & 196 \\
\hline Age (y) & $56.8 \pm 10.6(24-83)$ \\
\hline$\leq 65$ & $138(78.0)$ \\
\hline$>65$ & $39(22.0)$ \\
\hline \multicolumn{2}{|l|}{ Sex } \\
\hline Male & $44(24.9)$ \\
\hline Female & $133(75.1)$ \\
\hline \multicolumn{2}{|l|}{ Smoking status } \\
\hline Positive & $11(6.2)$ \\
\hline Negative & $166(93.8)$ \\
\hline \multicolumn{2}{|l|}{ Nodule numbers in each patient } \\
\hline 1 & $159(89.8)$ \\
\hline 2 & $17(9.6)$ \\
\hline 3 & $1(0.6)$ \\
\hline Nodule size $(\mathrm{mm})^{*}$ & $7.8 \pm 3.4(2-22)$ \\
\hline \multicolumn{2}{|l|}{ Nodule site } \\
\hline Left upper lobe & $49(25)$ \\
\hline Left lower lobe & $34(17.3)$ \\
\hline Right upper lobe & $59(30.1)$ \\
\hline Right middle lobe & $17(8.7)$ \\
\hline Right lower lobe & $37(18.9)$ \\
\hline \multicolumn{2}{|l|}{ Image characteristics } \\
\hline Pure GGN & $115(58.7)$ \\
\hline Part-solid GGN (GGO $\geq 50 \%$ ) & $39(19.9)$ \\
\hline Part-solid GGN (GGO < 50\%) & $23(11.7)$ \\
\hline Solid nodule & $19(9.7)$ \\
\hline \multicolumn{2}{|l|}{ Pathologic diagnosis } \\
\hline Benign & $18(9.2)$ \\
\hline Fibrosis & 8 \\
\hline Intrapulmonary lymph node & 4 \\
\hline Organizing pneumonia & 2 \\
\hline Tuberculoma & 2 \\
\hline Cryptococcosis & 1 \\
\hline Alveolar protenosis & 1 \\
\hline Primary lung cancer and precancerous lesions & $173(88.3)$ \\
\hline Invasive adenocarcinoma & 137 \\
\hline Adenocarcinoma in situ & 17 \\
\hline Atypical adenomatous hyperplasia & 7 \\
\hline Mucinous adenocarcinoma & 7 \\
\hline Minimally invasive adenocarcinoma & 5 \\
\hline Other malignancies & $5(2.6)$ \\
\hline Metastatic colon cancer & 3 \\
\hline Metastatic breast cancer & 1 \\
\hline MALToma & 1 \\
\hline
\end{tabular}

$S D$, Standard deviation; $G G N$, ground-glass nodule; $G G O$, ground-glass opacity; MALToma, mucosa-associated lymphoid tissue lymphoma. *Nodule size according to the pathology report.

complete. The procedure times in patients who underwent 1,2 , or 3 localizations were $20.9,39.1$, and 47 minutes, respectively. The mean time from completing the localization procedure to the initiation of surgery was 233.1 minutes (range, 80-561 minutes). Table 2 shows the details of CT-guided dye localization.
TABLE 2. Results of CT-guided localization

\begin{tabular}{lc}
\hline & $\begin{array}{c}\text { N }(\%) \text { or } \\
\text { mean } \pm \text { SD (range) }\end{array}$ \\
\hline Distance traversed by the needle $(\mathrm{mm})$ & \\
From the skin to the nodule & $59.2 \pm 17.1(23.3-110)$ \\
From the pleura to the nodule & $18.3 \pm 11.1(1-60)$ \\
Amount of dye injected $(\mathrm{mL})$ & $0.25 \pm 0.09(0.1-0.75)$ \\
CT localization procedure duration (min) & \\
All & $30.0 \pm 9.4(6-60)$ \\
One localization $(\mathrm{n}=158)^{*}$ & $20.9 \pm 6.6(6-51)$ \\
Two localizations $(\mathrm{n}=18)^{*}$ & $39.1 \pm 11.8(17-60)$ \\
Three localizations (n=1) & 47 \\
Duration from localization to surgery (min) & $233.1 \pm 87.0(80-561)$ \\
Localization-related complications & \\
Intrapulmonary focal hemorrhage & $96(54.2)$ \\
Pneumothorax & $52(29.4)$ \\
$\quad$ Small & 49 \\
Large $\dagger$ & 3 \\
Hemoptysis & $1(0.5)$ \\
Hemothorax & $0(0)$ \\
Allergic reaction & $0(0)$ \\
Complications need invasive management & $0(0)$ \\
Failed localization & $1(0.5)$ \\
\hline
\end{tabular}

$S D$, Standard deviation; $C T$, computed tomography. *One patient with 2 lung nodules underwent only 1 localization because the distance between the 2 nodules was close; 2 patients with 1 lung nodule underwent localization twice. $\dagger$ According to the 2010 British Thoracic Society guidelines, ${ }^{29}$ large pneumothorax is defined as lung margin to chest wall distance $\geq 2 \mathrm{~cm}$.

Localization-related complications included intrapulmonary focal hemorrhage $(54.2 \% ; 96 / 177)$, pneumothorax $(29.4 \% ; 52 / 177)$, and hemoptysis $(0.5 \% ; 1 / 177)$. We classified pneumothoraces as small or large according to the 2010 British Thoracic Society guidelines ${ }^{31}$ : the distance of the lung margin from the chest wall was less than $2 \mathrm{~cm}$ or $2 \mathrm{~cm}$ or more, respectively. Only 3 patients $(1.7 \%$; 3/177) had large pneumothoraces. All patients with complications received conservative treatment only, including oxygen therapy and observation. No invasive treatment was required to resolve the complications.

The localization procedure was performed successfully and correctly in $99.5 \%(195 / 196)$ of the nodules. In the only failed case, the patient had 2 pulmonary nodules located in the right upper and right lower lobes. After successful CT-guided dye localization of the right upper lobe nodule, a large pneumothorax occurred. The second procedure failed due to difficulty fixating the nodule because of the patient's inspiration. The patient received only oxygen therapy, and no chest tube was placed. During the operation, the location of the nodule that failed localization was determined according to the preoperative CT images. The nodule was successfully resected using uniportal VATS, without conversion to a minithoracotomy.

\section{Operative and Postoperative Results}

All nodules were successfully resected using uniportal VATS, without conversion to minithoracotomy or 
TABLE 3. Operative and postoperative results

\begin{tabular}{lc}
\hline & $\begin{array}{c}\text { N (\%) or } \\
\text { mean } \pm \text { SD (range) }\end{array}$ \\
\hline Surgical method & $154(87)$ \\
$\quad$ Uniportal VATS wedge resection & $13(7.3)$ \\
$\quad$ Uniportal VATS segmentectomy & $10(5.7)$ \\
$\quad$ Uniportal VATS lobectomy & $100(56.5)$ \\
Anesthetic method & $77(43.5)$ \\
$\quad$ Nonintubated anesthesia & $89.1 \pm 28.5(38-217)$ \\
$\quad$ Intubated anesthesia & $6.3 \pm 17.5(0-100)$ \\
Operation duration (min) & 0 \\
Operative bleeding (mL) & $3.3 \pm 1.2(1-10)$ \\
Postoperative ICU stay (d) & $1.5 \pm 0.9(0-5)$ \\
Postoperative hospital stay (d) & $0(0)$ \\
Postoperative chest tube duration (d) & $1(0.6)$ \\
Conversion* & 1 \\
Morbidity & $0(0)$ \\
$\quad$ Pneumonia & \\
Mortality & \\
\hline
\end{tabular}

$S D$, Standard deviation; VATS, video-assisted thoracoscopic surgery; $I C U$, intensive care unit. *Conversion to minithoracotomy or thoracotomy.

thoracotomy. The mean operative time was 89.1 minutes (range, 38-217 minutes). Most patients underwent uniportal VATS wedge resection $(87 \% ; 154 / 177)$. For the remaining 23 patients with malignancies confirmed by intraoperative frozen section and resection margins of less than $20 \mathrm{~mm}$, an additional anatomic pulmonary resection was performed. Thirteen patients $(7.3 \% ; 13 / 177)$ underwent uniportal VATS segmentectomy, and 10 patients $(5.7 \% ; 10 / 177)$ underwent uniportal VATS lobectomy. All patients $(n=177)$ with intraoperative frozen-section diagnoses of malignancy or precancerous lesions underwent additional systematic lymph node dissection.

The overall postoperative course was uneventful, with a mean hospital stay of 3.3 days (range, 1-10 days) and a low morbidity rate $(0.6 \% ; 1 / 177)$. The mean hospital stays were 3.7 days (range, 2-6 days) and 3.2 days (range, 15 days) in the segmentectomy and lobectomy groups, respectively. Only 1 patient developed postoperative morbidity of pneumonia and underwent 10 days of antibiotic treatment. Table 3 shows the operative and postoperative results.

\section{DISCUSSION}

PBV dye is an isomer of isosulfan blue and is widely used for sentinel lymphatic mapping in breast cancer surgery. ${ }^{32}$ A high rate of sentinel lymph node detection is achieved using PBV dye. The advantage of this method includes cost effectiveness and safety. Allergic reactions to PBV are rare, with a reported incidence of $0.07 \%$ to $2.7 \% .^{32,33}$ Use of PBV dye in preoperative CT-guided pulmonary nodule localization has not yet been reported in the literature. Initially, we used methylene blue dye for preoperative CT-guided pulmonary nodule localization. However, the dye rapidly diffused into the surrounding lung parenchyma in some patients. Several studies reported this disadvantage, ${ }^{10,13,14}$ which hindered the use of methylene blue. Therefore, we began using PBV dye for pulmonary nodule localization in 2013.

Several intraoperative and preoperative localization methods have been described for small pulmonary nodules. Most of the methods have their advantages and disadvantages, and may not be useful in uniportal VATS. Table 4 provides a comparison of CT-guided PBV localization and other frequently used CT-guided localization methods. $^{13-23}$

There are several advantages of CT-guided PBV localization. (1) The localization success rate is high, even in patients with synchronous multiple pulmonary nodules. (2) The technique is applicable to nodules located deeper in the lung parenchyma. (3) CT-guided biopsy technical components and equipment are readily available without additional cost, and radiologists and surgeons are not exposed to radiation. (4) The localization procedure requires a short time to complete. (5) Localization does not require immediate surgery on completion. (6) The procedure causes minimal localization- and surgery-related morbidity. The disadvantage of this method is a possible allergic reaction to PBV dye. However, this allergic reaction is rare and often minor. $^{32,33}$

The localization success rate in the study was high at $99.5 \%(195 / 196)$; it was $100 \%(159 / 159)$ in patients with a single nodule and $97.2 \%(36 / 37)$ in those with synchronous multiple nodules. Synchronous, multiple, small lung tumors have increased in frequency during the last decade, particularly in Asia. 3,34,35 Most synchronous, multiple, small lung tumors were adenocarcinomas characterized by pure or mixed GGO on CT and a good prognosis after surgical treatment. ${ }^{3,34,35}$ Most of the pulmonary nodules $(78.6 \%)$ in this study were pure GGN and part-solid GGN with GGO of $50 \%$ or more. These patients were easily treated with uniportal VATS using preoperative CTguided PBV dye localization. For some patients with a deep nodule, the pleural surface of the localization route and the nodule site were both localized with PBV dye (Figure 4, $A$ and $B$ ). Therefore, surgeons could easily and quickly locate the lesion site, estimate the depth of the nodule, and decide on an adequate surgical margin. Nodules in other unsatisfactory sites such as the apical pleural surface, the paraaortic pleural surface, and the diaphragmatic pleural surface could also be easily localized (Figure E3).

In this study, we have demonstrated that CT-guided PBV dye localization is a simple and feasible procedure for preoperative nodule localization. The mean procedure duration was $20.9 \pm 6.6$ minutes in patients who underwent 1 localization procedure, and the mean amount of dye injected was only $0.25 \pm 0.09 \mathrm{~mL}$. There is no requirement for 
TABLE 4. Summary of preoperative CT-guided localization methods for indeterminate pulmonary nodules

\begin{tabular}{|c|c|c|c|c|c|}
\hline & Patients/nodules (n) & $\begin{array}{c}\text { Tumor } \\
\text { size }(\mathbf{m m})\end{array}$ & $\begin{array}{c}\text { Lesion } \\
\text { depth }(\mathbf{m m})\end{array}$ & $\begin{array}{l}\text { Procedure } \\
\text { time (min) }\end{array}$ & Complications \\
\hline $\begin{array}{l}\text { CT-guided PBV dye injection } \\
\text { (current study) }\end{array}$ & $177 / 196$ & 7.8 & 18.3 & $30.0^{*}$ & $\begin{array}{l}\text { Pneumothorax: } 29.4 \% \\
\text { Intrapulmonary focal } \\
\text { hemorrhage: } 54.2 \% \\
\text { Hemoptysis: } 0.5 \%\end{array}$ \\
\hline $\begin{array}{l}\text { CT-guided methylene blue dye } \\
\text { injection }^{13,14}\end{array}$ & $32 / 36$ & 11.9 & 8.8 & $32^{14}$ & Pneumothorax: $33 \%{ }^{14}$ \\
\hline $\begin{array}{l}\text { CT-guided hookwire } \\
\text { placement }^{15-18}\end{array}$ & $311 / 313$ & 12.1 & 12.3 & $24.7^{15,17}$ & $\begin{array}{l}\text { Pneumothorax: } 29.2 \% \\
\text { Hookwire dislodgment: } 5.4 \% \\
\text { Hemothorax: } 0.5 \% \\
\text { Intrapulmonary focal } \\
\text { hemorrhage: } 36 \%{ }^{18}\end{array}$ \\
\hline CT-guided coil labeling ${ }^{19}$ & $14 / 15$ & $5-20$ & $5-30$ & N/A & $\begin{array}{l}\text { Pneumothorax: } 20 \% \\
\text { Coil migration: } 6.7 \%\end{array}$ \\
\hline CT-guided lipiodol marking ${ }^{20-22}$ & $194 / 222$ & 10.7 & 10.6 & $27.5^{20}$ & $\begin{array}{l}\text { Pneumothorax: } 17 \%{ }^{21} \\
\text { Pneumothorax required } \\
\text { drainage: } 6 \%{ }^{21} \\
\text { Hemoptysis: } 6 \%^{21} \\
\text { Hemothorax: } 0.6 \%^{21}\end{array}$ \\
\hline $\begin{array}{l}\text { CT-guided radiotracer } \\
\text { placement }^{23}\end{array}$ & $211 / 211$ & 8.3 & 13.0 & N/A & Pneumothorax: $10.4 \%$ \\
\hline
\end{tabular}

$C T$, Computed tomography; $P B V$, patent blue vital; VATS, video-assisted thoracoscopic surgery; N/A, not available. *The procedure time was 20.9 minutes in patients who underwent 1 localization procedure.

involvement of facilities such as a fluoroscope, radiotracer, radioprobe, hookwire, coil, or contract injection. Radiologists and surgeons do not receive any radiation exposure. The mean duration from localization to surgery was $233.1 \pm 87.0$ minutes in this study. The margin of the localization site was clearly visible long after PBV dye injection (Figure 5, A). This is an advantage when the subsequent operation start time is unpredictable. Only minimal complications were observed in the study group.

Complications of asymptomatic intrapulmonary focal hemorrhage and pneumothorax occurred in $54.2 \%$ and $29.4 \%$ patients, respectively. Only 1 patient had hemoptysis after the procedure. No allergic reaction occurred. We defined patients with intrapulmonary focal hemorrhage and pneumothorax according to the findings of postprocedural CT scans. Patients with minimal intrapulmonary focal hemorrhage and minimal pneumothorax constituted the complication group. Nonetheless, complications in these patients were considered minor, and they received conservative treatment consisting of observation and oxygen therapy only.

Uniportal VATS is feasible with perioperative outcomes comparable with those of traditional 3-port VATS. ${ }^{8,9}$ Uniportal VATS for pulmonary nodule excision, including wedge resection, segmentectomy, and lobectomy, was performed in all of the study patients. Preoperative CTguided PBV dye localization makes poorly visible, impalpable, small nodules visible under direct thoracoscopic view. We attribute our short uniportal VATS duration (89.1 minutes), minimal operative blood loss $(6.3 \mathrm{~mL})$, short postoperative hospital stay (3.3 days), and low morbidity rate $(0.6 \%)$ to preoperative CT-guided PBV dye localization. No intraoperative conversion to thoracotomy and no mortality occurred.

We acknowledge that there are limitations to this study. As a single-institute, retrospective study, patient-selection and time-trend bias were inevitable. Our short study period should help to minimize time-trend bias. To the best of our knowledge, no previous reports have described the use of PBV dye for preoperative CT-guided pulmonary nodule localization. We reported our experience with a large cohort of 177 consecutive patients who underwent uniportal VATS for resection of 196 indeterminate pulmonary nodules. Prospective multi-institutional studies are needed to validate the safety and efficacy of CT-guided PBV dye localization. Further research is also necessary to compare this new technique with previously established localization methods, and should focus on the diagnostic yield, complication rate, and cost effectiveness of these different methods.

\section{CONCLUSIONS}

Our study demonstrated that preoperative CT-guided PBV dye localization is a feasible, safe, and accurate procedure. Use of this localization method enables surgeons to resect small, deeply located, GGO predominant, 
TABLE 4. Continued

\begin{tabular}{|c|c|c|c|}
\hline Surgical method & $\begin{array}{l}\text { Conversion } \\
\text { rate }(\%)\end{array}$ & Advantages & Disadvantages \\
\hline Uniportal VATS & 0 & $\begin{array}{l}\text { High accuracy, safe, fast, cost } \\
\text { effective, no radiation exposure }\end{array}$ & Allergy (rare) \\
\hline VATS & 12.5 & $\begin{array}{l}\text { Safe, fast, cost effective, no } \\
\text { radiation exposure }\end{array}$ & $\begin{array}{l}\text { Diffusion into surrounding lung, } \\
\text { allergy (rare) }\end{array}$ \\
\hline VATS & 3.9 & Safe, fast, no radiation exposure & Hookwire dislodgment \\
\hline VATS & 7.1 & Stable & $\begin{array}{l}\text { Coil migration, radiation } \\
\text { exposure }\end{array}$ \\
\hline VATS & $0^{21,22}$ & $\begin{array}{l}\text { High accuracy, real-time verifies } \\
\text { stapled margin }\end{array}$ & $\begin{array}{c}\text { Radiation exposure, fluoroscopy } \\
\text { dependent, contrast allergy }\end{array}$ \\
\hline VATS & 0.5 & $\begin{array}{l}\text { High accuracy, real-time } \\
\text { verifying stapled margin, low } \\
\text { complication rate }\end{array}$ & $\begin{array}{l}\text { Radiation exposure, gamma ray } \\
\text { detector dependent }\end{array}$ \\
\hline
\end{tabular}

synchronous, multiple, indeterminate pulmonary nodules smoothly by uniportal VATS. Thus, patients can achieve good perioperative and postoperative outcomes.

\section{Conflict of Interest Statement}

Authors have nothing to disclose with regard to commercial support.

\section{References}

1. Krochmal R, Arias S, Yarmus L, Feller-Kopman D, Lee H. Diagnosis and management of pulmonary nodules. Expert Rev Respir Med. 2014;8:677-91.

2. Raad RA, Suh J, Harari S, Naidich DP, Shiau M, Ko JP. Nodule characterization: subsolid nodules. Radiol Clin North Am. 2014;52:47-67.

3. Naidich DP, Bankier AA, MacMahon H, Schaefer-Prokop CM, Pistolesi M, Goo JM, et al. Recommendations for the management of subsolid pulmonary nodules detected at CT: a statement from the Fleischner Society. Radiology. 2013;266:304-17

4. Shimizu K, Ikeda N, Tsuboi M, Hirano T, Kato H. Percutaneous CT-guided fine needle aspiration for lung cancer smaller than $2 \mathrm{~cm}$ and revealed by ground-glass opacity pulmonary lesions. Am J Roentgenol. 2008;190:234-9.

5. Yeow KM, Tsay PK, Cheung YC, Lui KW, Pan KT, Chou AS. Factors affecting diagnostic accuracy of CT-guided coaxial cutting needle lung biopsy: retrospective analysis of 631 procedures. J Vasc Interv Radiol. 2003; 14:581-8.

6. Nakao M, Yoshida J, Goto K, Ishii G, Kawase A, Aokage K, et al. Long-term outcomes of 50 cases of limited-resection trial for pulmonary ground-glass opacity nodules. J Thorac Oncol. 2012;7:1563-6.

7. Yoshida J, Ishii G, Hishida T, Aokage K, Tsuboi M, Ito H, et al. Limited resection trial for pulmonary ground-glass opacity nodules: case selection based on high-resolution computed tomography-interim results. Jpn J Clin Oncol. 2015; 45:677-81.

8. Gonzalez D, Paradela M, Garcia J, Dela Torre M. Single-port video-assisted thoracoscopic lobectomy. Interact Cardiovasc Thorac Surg. 2011;12:514-5.
9. Rocco G, Martucci N, La Manna C, Jones DR, De Luca G, La Rocca A, et al. Ten-year experience on 644 patients undergoing single-port (uniportal) video-assisted thoracoscopic surgery. Ann Thorac Surg. 2013;96:434-8.

10. Daniel TM. A proposed diagnostic approach to the patient with the subcentimeter pulmonary nodule: techniques that facilitate video-assisted thoracic surgery excision. Semin Thorac Cardiovasc Surg. 2005;17:115-22.

11. Keating JJ, Kennedy GT, Singhal S. Identification of a subcentimeter pulmonary adenocarcinoma using intraoperative near-infrared imaging during video-assisted thoracoscopic surgery. J Thorac Cardiovasc Surg. 2015;149: e51-3.

12. Matsuura Y, Mun M, Nakagawa K, Okumura S. Efficacy and feasibility of a novel and noninvasive computed tomography-guided marking technique for peripheral pulmonary nodules. J Thorac Cardiovasc Surg. 2015;149:1208-9.

13. McConnell PI, Feola GP, Meyers RL. Methylene blue-stained autologous blood for needle localization and thoracoscopic resection of deep pulmonary nodules. J Pediatr Surg. 2002;37:1729-31.

14. Lenglinger FX, Schwarz CD, Artmann W. Localization of pulmonary nodules before thoracoscopic surgery: value of percutaneous staining with methylene blue. AJR Am J Roentgenol. 1994;163:297-300.

15. Ciriaco P, Negri G, Puglisi A, Nicoletti R, Del Maschio A, Zannini P. Video-assisted thoracoscopic surgery for pulmonary nodules: rationale for preoperative computed tomography-guided hookwire localization. Eur J Cardiothorac Surg. 2004;25:429-33.

16. Chen S, Zhou J, Zhang J, Hu H, Luo X, Zhang Y, et al. Video-assisted thoracoscopic solitary pulmonary nodule resection after CT-guided hookwire localization: 43 cases report and literature review. Surg Endosc. 2011:25:1723-9.

17. Chen YR, Yeow KM, Lee JY, Su IH, Chu SY, Lee CH, et al. CT-guided hook wire localization of subpleural lung lesions for video-assisted thoracoscopic surgery (VATS). J Formos Med Assoc. 2007;106:911-8.

18. Seo JM, Lee HY, Kim HK, Choi YS, Kim J, Shim YM, et al. Factors determining successful computed tomography-guided localization of lung nodules. J Thorac Cardiovasc Surg. 2012;143:809-14.

19. Lizza N, Eucher P, Haxhe JP, De Wispelaere JF, Johnson PM, Delaunois L. Thoracoscopic resection of pulmonary nodules after computed tomographicguided coil labeling. Ann Thorac Surg. 2001;71:986-8. 
20. Moon SW, Wang YP, Jo KH, Kwack MS, Kim SW, Kwon OK, et al. Fluoroscopy-aided thoracoscopic resection of pulmonary nodule localized with contrast media. Ann Thorac Surg. 1999;68:1815-20.

21. Watanabe K, Nomori H, Ohtsuka T, Kaji M, Naruke T, Suemasu K. Usefulness and complications of computed tomography-guided lipiodol marking for fluoroscopy-assisted thoracoscopic resection of small pulmonary nodules: experience with 174 nodules. J Thorac Cardiovasc Surg. 2006;132:320-4.

22. Nomori H, Horio H, Naruke T, Suemasu K. Fluoroscopy-assisted thoracoscopic resection of lung nodules marked with lipiodol. Ann Thorac Surg. 2002;74:170-3.

23. Ambrogi MC, Melfi F, Zirafa C, Lucchi M, De Liperi A, Mariani G, et al. Radio-guided thoracoscopic surgery (RGTS) of small pulmonary nodules. Surg Endosc. 2012;26:914-9.

24. Finley RJ, Mayo JR, Grant K, Clifton JC, English J, Leo J, et al. Preoperative computed tomography-guided microcoil localization of small peripheral pulmonary nodules: a prospective randomized controlled trial. J Thorac Cardiovasc Surg. 2015;149:26-31.

25. Doo KW, Yong HS, Kim HK, Kim S, Kang EY, Choi YH. Needlescopic resection of small and superficial pulmonary nodule after computed tomographic fluoroscopy-guided dual localization with radiotracer and hookwire. Ann Surg Oncol. 2015;22:331-7.

26. Sato M, Omasa M, Chen F, Sato T, Bando T, Date H. Use of virtual assisted lung mapping (VAL-MAP), a bronchoscopic multi-spot dye-marking technique using virtual images, for precise navigation of thoracoscopic sublobar lung resection. J Thorac Cardiovasc Surg. 2014;147:1813-9.

27. Khereba M, Ferraro P, Duranceau A, Martin J, Goudie E, Thiffault V, et al Thoracoscopic localization of intraparenchymal pulmonary nodules using direct intracavitary thoracoscopic ultrasonography prevents conversion of VATS procedures to thoracotomy in selected patients. J Thorac Cardiovasc Surg. 2012;144:1160-5.

28. Hung MH, Chan KC, Liu YJ, Hsu HH, Chen KC, Cheng YJ, et al. Nonintubated thoracoscopic lobectomy for lung cancer using epidural anesthesia and intercostal blockade: a retrospective cohort study of 238 cases. Medicine (Baltimore). 2015;94:e727.

29. Hung MH, Cheng YJ, Chan KC, Han SC, Chen KC, Hsu HH, et al. Nonintubated uniportal thoracoscopic surgery for peripheral lung nodules. Ann Thorac Surg. 2014;98:1998-2003

30. Chen JS, Cheng YJ, Hung MH, Tseng YD, Chen KC, Lee YC Nonintubated thoracoscopic lobectomy for lung cancer. Ann Surg. 2011;254 1038-43.

31. MacDuff A, Arnold A, Harvey J, BTS Pleural Disease Guideline Group Management of spontaneous pneumothorax: British Thoracic Society Pleural Disease Guideline 2010. Thorax. 2010;65(Suppl 2):ii18-31.

32. Tong M, Gou W, Gao W. Use of fluorescence imaging in combination with patent blue dye versus patent blue dye alone in sentinel lymph node biopsy in breast Cancer. J Breast Cancer. 2014;17:250-5.

33. Barthelmes L, Goyal A, Sudheer P, Mansel RE. Investigation of anaphylactic reaction after patent blue V dye injection. Breast. 2010; 19:516-20.

34. Lin MW, Wu CT, Kuo SW, Chang YL, Yang PC. Clinicopathology and genetic profile of synchronous multiple small adenocarcinomas: implication for surgical treatment of an uncommon lung malignancy. Ann Surg Oncol. 2014;21:2555-62.

35. Kozower BD, Larner JM, Detterbeck FC, Jones DR. Special treatment issues in non-small cell lung cancer: Diagnosis and management of lung cancer, 3rd ed: American College of Chest Physicians evidence-based clinical practice guidelines. Chest. 2013;143:e369S-99S.

Key Words: computed tomography-guided localization, lung tumor, patent blue vital dye, uniportal surgery, videoassisted thoracoscopic surgery

Readers who found these articles interesting may also like to read the following papers found in recent and future issues of our sister publications, Seminars in Thoracic and Cardiovascular Surgery and Operative Techniques in Thoracic and Cardiovascular Surgery!

Thoracic: Thoracic Oncology

Original Submission: The 3-Hole Minimally Invasive Esophagectomy: A Safe Procedure Following Neoadjuvant Chemotherapy and Radiation. Rona Spector. Semin Thorac Cardiovasc Surg 2015; Summer; 27(2): 205-215.

Editorial Commentary: With Minimally Invasive Esophagecomty, Thoracic Surgeons Must Avoid Falling Into the Same Trap Again Thomas Ng. Semin Thorac Cardiovasc Surg 2015; Summer; 27(2):216.

Original Submission: Maximal Oxygen Uptake - Risk Predictor of NSCLC Resection with Comorbid Emphysema: Lessons from NETT. Ian Makey. Semin Thorac Cardiovasc Surg 2015; Summer; 27(2):225-224.

Editorial Commentary: How Can the NETT Provide Guidance in Risk Stratification for Patients with Severe Emphysema and Early Stage NSCLC? Michael Hsin. Semin Thorac Cardiovasc Surg 2015; Summer; 27(2):232-233.

State of the Art: Induction Therapy for Mesothelioma. Isabelle Schmitt-Opitz. Semin Thorac Cardiovasc Surg 2015; Summer; 27(2):240-250. 

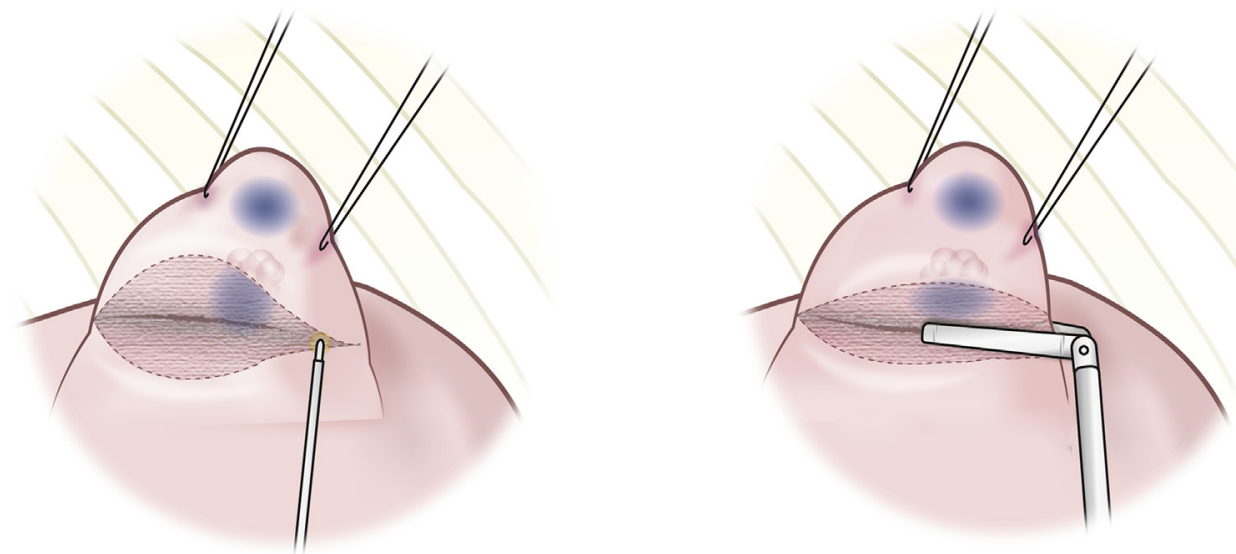

FIGURE E1. Surgical skills of uniportal video-assisted thoracoscopic surgery wedge resection for those lesions that were deep to the visceral pleural surface.
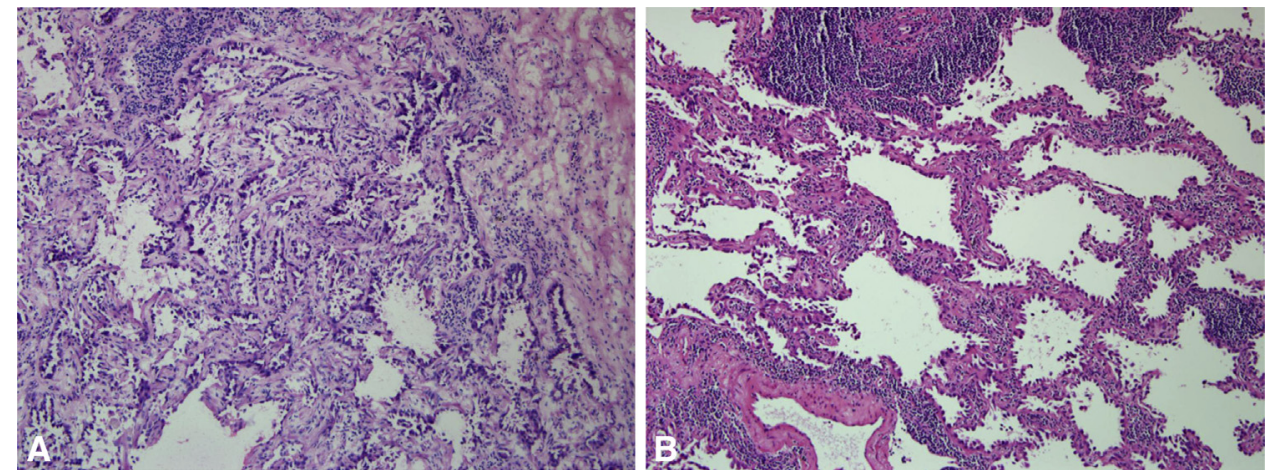

FIGURE E2. The frozen section (A) and permanent section (B) of the pulmonary nodules was clear for a pathologic diagnosis after PBV dye localization. The patient underwent uniportal VATS RML wedge resection for tissue proof at first. The frozen-section pathology report revealed invasive adenocarcinoma. Additional lobectomy for adequate section margin and systemic lymph node dissection were then performed. Permanent section pathology report revealed invasive adenocarcinoma with mixed lepidic $(60 \%)$ and acinar $(40 \%)$ patterns. 

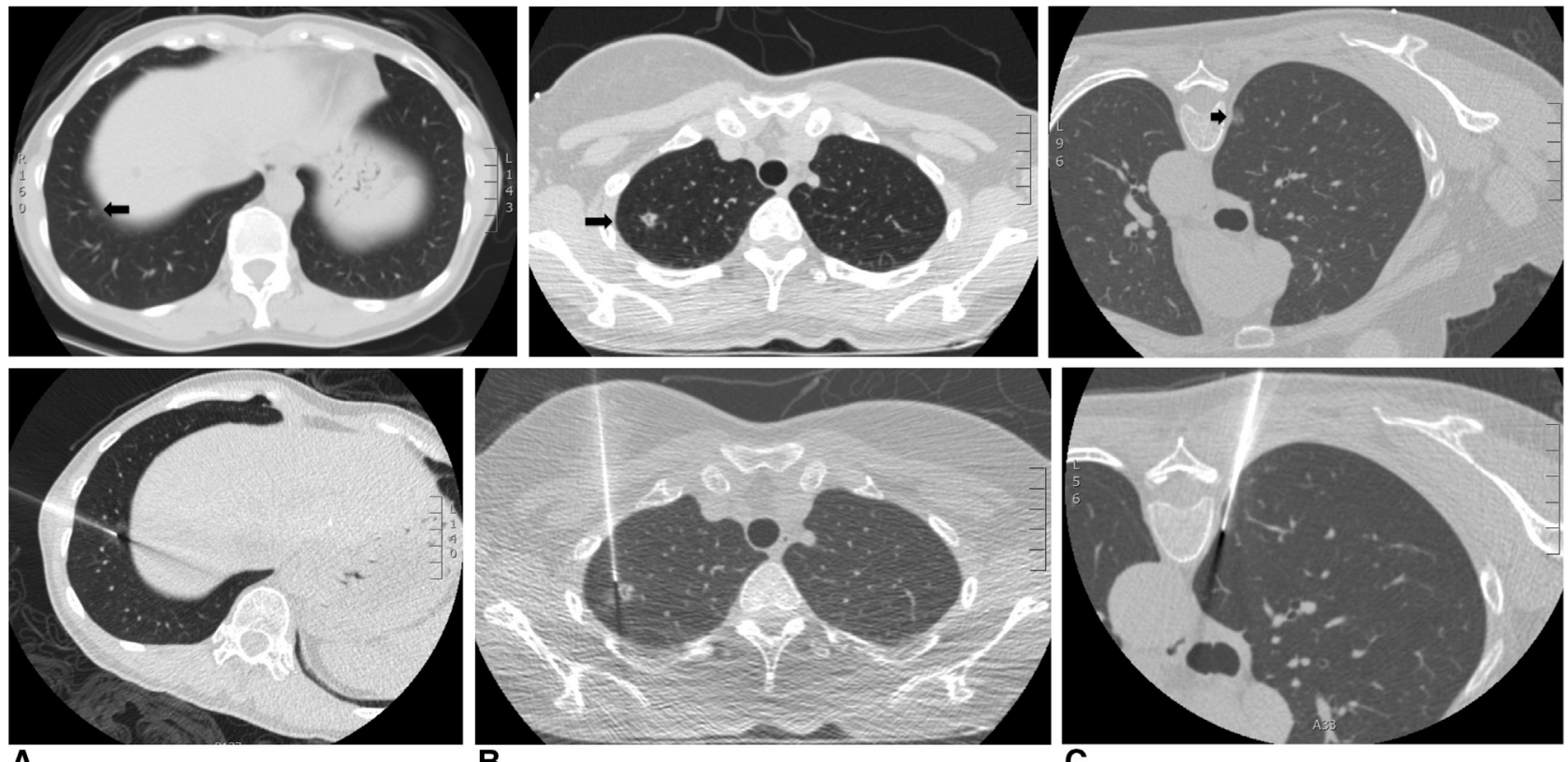

A

B
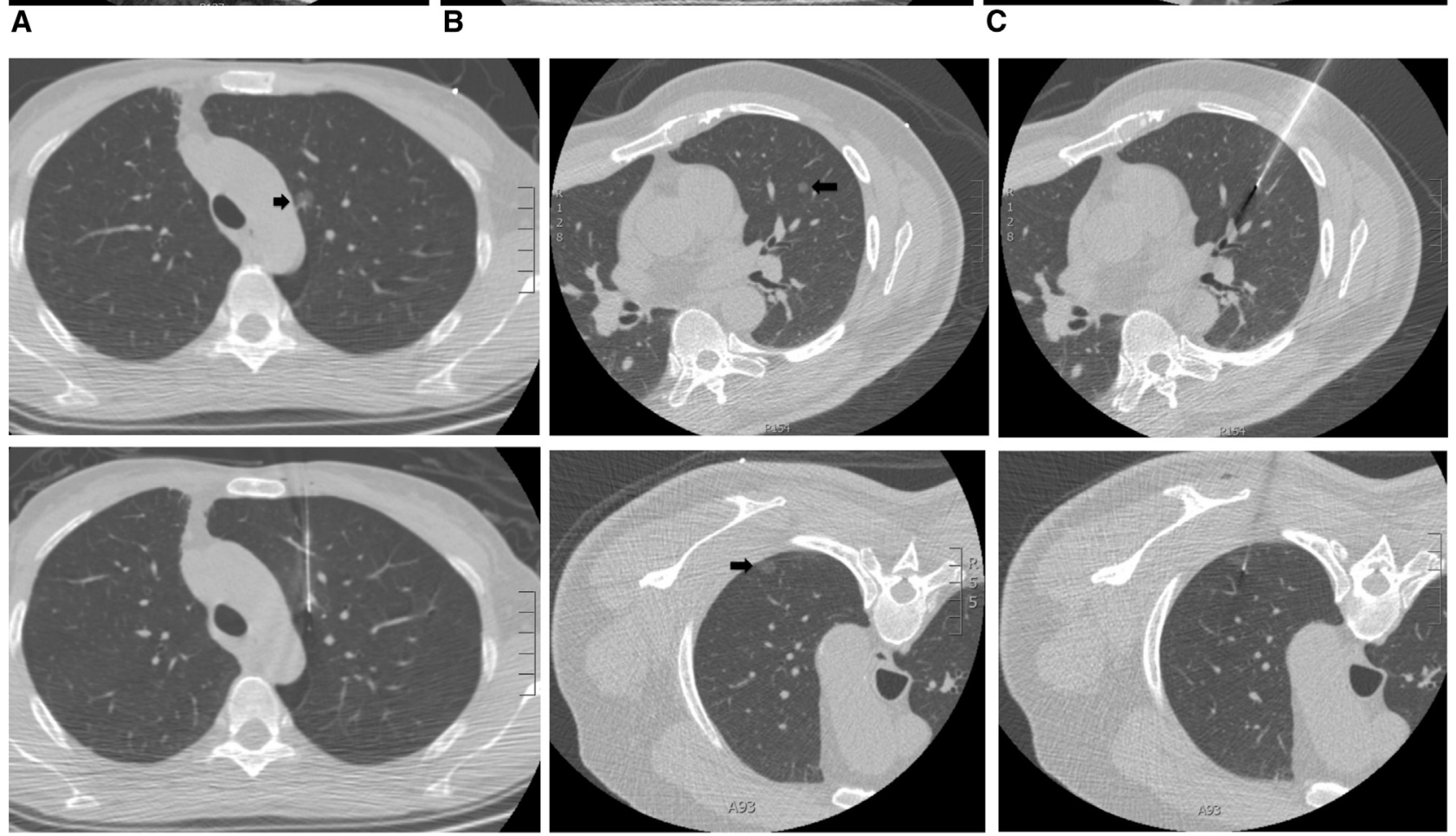

D

E

FIGURE E3. Nodules located at unsatisfactory sites for CT-guided hookwire localization were localized smoothly using the CT-guided PBV dye technique. A, The nodule (arrow) is located near the diaphragm. The pathology report revealed invasive adenocarcinoma with mixed acinar (40\%) and lepidic $(60 \%)$ patterns. B, The nodule (arrow) is located in the apex area. The pathology report revealed fibrosis. C, The nodule (arrow) is located in the paraspinal area. The pathology report revealed invasive adenocarcinoma with a predominantly papillary pattern. D, The nodule (arrow) is located near the aortic arch. The pathology report revealed invasive adenocarcinoma with a predominantly lepidic pattern. E, The nodules (arrows) are located in the bilateral lung fields, and the left nodule is deep in the lung parenchyma. The pathology report revealed invasive adenocarcinoma with mixed acinar (40\%) and lepidic (60\%) patterns for the left upper lobe nodule and adenocarcinoma in situ for the right lower lobe nodule. 